\title{
Geoportals as Sources of Information About the Territory
}

\author{
Grigory Lobanov ${ }^{[0000-0003-3764-7804]}$, Olga Moskalenko ${ }^{[0000-0003-1520-9926]}$ \\ Bryansk State Academician I.G. Petrovski University, \\ Russia, 241036, Bryansk, Bezhitskaya str., 14 \\ lobanov_grigorii@mail.ru, asik54@mail.ru
}

\begin{abstract}
The object of the article are popular geoportals (Yandex Maps, Google maps, 2GIS) as terrain models. The definition of geoportals and their structure and functions are described. It is noted that due to the high rate of development of the structure and content of geoportals, their functional capabilities and properties as an information resource do not have a sufficient scientific and methodological description. The content, functionality, and semiotics of geoportals are described. Special features of transmitting positional and attribute characteristics of natural and economic objects are noted; the significance of the main methods of automatic collection of information about the territory is revealed; five systems of conventional signs used in geoportals to create an image of the territory are identified and described. Similarities and differences of geoportals with traditional spatial models-topographic plans, geographic and thematic maps and plans are considered. The role of users in shaping the content, structure, and functional capabilities of geoportals is shown. Possible directions of development of geoportals sources as sources of terrain data are discussed.
\end{abstract}

Keywords: Geoportals, Hybrid Geoimages, Sign Systems, Cartographic Works, Information.

\section{Introduction}

Geoportals are a type of information resources that provide integration, visualization, updating and dissemination of spatial data based on Internet technologies [1, 2, 3, 4]. From the point of view of Geoinformatics theory, geoportals are a variant of network GIS, which are characterized by a large volume of integrated data, intuitively understandable interface aimed at users without special training, and a small set of functions for automatic spatial analysis. Geoportals are widely used in solving scientific, industrial and household tasks as a source of detailed information about the area and a means of managing geographical data. Popular cartographic services provide customizable ${ }^{1}$ visualization of geo-images (maps, satellite images, and their hybrids); search for terrain features, interactive navigation in the image space; cartometric operations; adding

Copyright c 2019 for this paper by its authors. Use permitted under Creative Commons License Attribution 4.0 International (CC BY 4.0). 
new objects by users, and some elements of mathematical cartographic modeling (generation of profiles, visibility-invisibility zones). The term "geo-image" here refers to photographic (space, aerial photos) and figurative-symbolic (maps) models of the earth's surface, which convey the relative location, size, distinctive features and properties (attributes) of objects located on it [5].

The relevance of the idea of geoportals as integrators of information about the area is confirmed by the development of existing and new information resources. The quantity and quality of spatial data is growing on existing resources, and services for managing them are becoming more diverse and convenient. However, even the most popular resources are not without disadvantages, which are often manifested in solving research and production tasks. This circumstance is associated with the prospects for the development of new information resources. In particular, the digital Earth project assumes high spatial resolution and rapid updating of remote sensing data that make up a significant part of the volume of information about the area on geoportals.

Trends in the evolution of the content, design, and management tools of geoportals allow us to believe that it is a leading factor in the mass demand of users for information about the area and services that provide work with it. At the same time, the continuity of geoportals from the spatial models of classical cartography is obvious, first of all, similar to them in the content and purpose of topographic maps and plans. The main content of classical and modern models is information about the mutual location, configuration, quantitative and qualitative properties of the earth's surface objects.

The study and reflection of the possibilities, prospects and limitations of using geoportals as spatial models does not keep pace with the pace of their technological improvement. The situation reflects the action of several factors: the development of computer graphics and modeling tools, the growth of the possibilities of computer networks in transmitting large amounts of information; the lack of a conceptual cartography apparatus for describing modern spatial models, and finally, the novelty of the process of their interactive construction by users. The relevance of studying and reflecting on the experience of using geoportals is not limited to theoretical interest, but is related to the search for promising directions for their development. This article presents the results of studying the properties of geoportals as spatial models, based on many years of experience in solving geographical research problems.

\section{Research objects}

Spatial models placed on geoportals are represented by geo-images of different origin and level of generalization, reduced to a single mathematical basis and consistent in design. The model space can be completely or partially filled with image elements. In the first case, these are "tiles" that make up satellite images or map images of different levels of generalization ("schematic") in the most common definition. In the second case, these are vector, raster, or 3D objects localized in space. Similar objects make up the main structural elements of the spatial model-layers of the electronic map. Combinations of layers form so-called hybrid geo-images. The structure described above is 
implemented in the most popular geoportals - Yandex maps, Google Earth, 2GIS, SASplanet, based on the experience of using them, the results obtained below $[6,7,8,9]$.

\section{Results and discussion}

Features of geoportals, as well as other spatial models, are revealed by three key properties: the content of information about the area, functionality, and semiotics.

Information about the area presented on geoportals includes primarily topographic information - i.e., positional (configuration, position in space) and attribute characteristics (properties) of objects on the earth's surface. The characteristics of the objects to vary in detail. Positional characteristics of natural and social objects with clear boundaries are transmitted with great accuracy and detail (in accordance with the resolution of satellite images), including: residential and industrial buildings, transport networks, and hydrographic networks. There are two ways to transmit information about relief on geoportals. The first is indirectly, through the change of surface types, which reflects the change of natural conditions, and, consequently, the change of landscapes. A large number of assumptions and uncertainties in this chain partially compensate for the second method - through information about the heights of individual points above sea level, which are reported on geoportals that use DEM data. Both data sources transmit surface morphology implicitly and in this sense are inferior to topographic plans and maps as terrain models (Fig. 1).

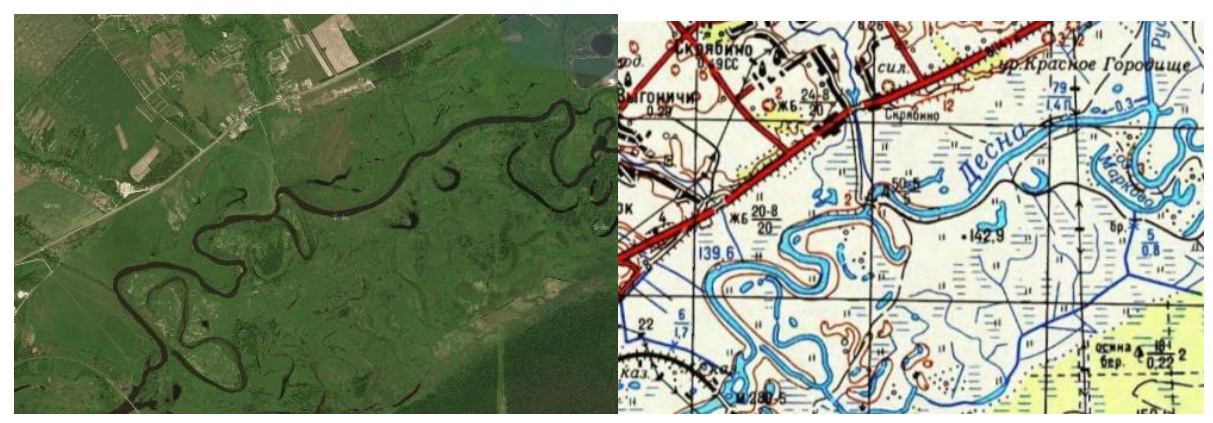

Fig. 1. Differences in representation of surface morphology on topographic maps and geoportals. The actual height difference between the river valley and the watershed (about $45 \mathrm{~m}$ ) in the satellite image is expressed indirectly by the arable areas in the upper - left corner.

Attribute characteristics are given mainly for objects in the service sector, in much more detail than on topographic maps. Information about the properties of hydrological objects, the composition and quality of vegetation, the purpose and performance characteristics of engineering structures (bridges, roads, Railways, industrial enterprises) that are typical for topographic and survey maps is not explicitly present on geoportals.

The functionality of geoportals as spatial models is most clearly shown in the automation of methods for obtaining information about the area. Automation largely determines the advantage and popularity of geoportals as sources of geographical information over cartographic works. In our opinion, three functions are most important: 
integration of geo-images of different scales, object search, and interactive planning and altitude measurements.

The first function is essential for performing classical tasks of geography - evaluating and describing the location of an object or territory. This function is provided by an interactive transition between scales, which allows you to see the regularities of the relative location of objects in the space and the features of the territory structure. Before creating geoportals, similar tasks were solved by comparing maps of different scales. Individual cartographic works provide a complete perception of areas from the first tens to several hundred thousand square kilometers. Changing the scale provides a gradual "immersion in the area", revealing the image of the territory.

The second function develops and automates methods for working with geographical name indexes, which are usually included in atlases for orientation on small-and medium - scale General geographic maps. On large-scale (topographical) maps, geographical names are not used-the search is performed within the borders of the sheets (in accordance with the purpose of the map), so it is often very time-consuming. Geoportals provide search for objects by accessing extensive databases of spatial data that contain the coordinates of the largest (most popular) part of objects mapped on topographic maps and plans, including: small settlements, rivers and lakes, individual structures and enterprises, roads and streets. However, the spatial databases of geoports do not yet contain certain types of objects, both those included in the state registers of geographical names (for example, tracts) and others marked on topographic maps (in particular, forest management blocks).

The third function significantly reduces the complexity of various cartometric operations-measuring distances, areas, and heights. At the same time, technological and methodological features of interactive measurements form the problem of correct interpretation of morphometric differences in the characteristics of the same objects on topographic materials and hybrid images. The need for comparisons is due to a very common way to assess the dynamics of objects-by comparing their borders on differenttime images. Usually topographic maps and plans created several decades ago are compared with recent high-resolution satellite images. The difference in morphometric characteristics, in addition to the actual changes in time, is due to the generalization of the image of the borders of objects on topographical materials. Especially cartographic generalization distorts the contours of small objects with a complex configuration of channels of small rivers, the shoreline of lakes. Satellite images, on the other hand, convey the configuration in as much detail as possible, so that the results of quantifying changes are often uncertain and replaced with qualitative indicators.

Semiotic features of geoportals consist in the use of different, complementary sign systems. Technological solutions of the most popular geoportals allow us to talk about five mutually fulfilling sign systems that differ in their purpose, level of development and way of perception of information about the area. Individual geoportals implement their capabilities differently, specializing in either visual effects (Google Earth) or detailed descriptions (Yandex maps).

The first system is formed by satellite images that fill the model space. Images convey the features of the area through the mutual location and the ratio of different types of surface - forest, open space, industrial and civil development. Potentially, satellite 
images in ultra-high and high resolution contain more information than General geographic maps, the saturation of which is limited by a group of factors-from the size of the sheet, the criteria and standards for selecting objects to the difficulties of psychological perception of complex signs. However, the identification, as well as the quantitative and qualitative characteristics of objects depicted on satellite images, without much experience in decryption are determined approximately. Fragments of satellite images can often not be reliably identified without extensive user experience in working with remote sensing materials.

The second system is formed by conventional signs of electronic maps, which complement satellite images and provide recognition of objects that are most in demand by users. Electronic maps are the most informative elements of the spatial model. The system is based on associative signs, which are supplemented with interactive descriptions, photos, and dynamic elements. Extensions report important consumer properties of objects, such as opening hours, quality of services, and availability. The idea of some properties of objects is formed only visually. For example, the characteristics of highways on the Yandex maps geoportal are displayed via photos. The description of objects that are less interesting to the average user - undeveloped territories, agricultural landscapes, woodlands and water areas-is limited by their belonging to administrative divisions and their names (if available). The system of symbols for electronic maps is significantly simpler in comparison with topographic maps and plans. First, the number of variants of signs does not exceed the first dozen, whereas on topographic maps and plans about 500 are used $[10,11]$. Signs on electronic maps are used primarily to indicate objects of buildings and services, while numerous engineering structures and natural objects are ignored by developers of electronic maps (Fig. 2). Secondly, the internal structure of conventional signs that allows you to convey a variety of properties of the same type of objects (for example, roads, borders, engineering structures) is not used. The simplicity of the system of symbols is confirmed by the absence or very simple version of the legend without additional explanations.

The third system consists of hyperlinks to photos and video clips, designed as placemarks. The density of signs indirectly characterizes the suitability, significance and popularity of objects for recreation and tourism. The fourth and fifth systems are threedimensional objects and terrain models that form the presence effect. Specific information in this system, as well as in satellite images, is not clearly present - through a visa-assessed level of improvement, the attractiveness of architecture. Currently, the development of systems is technologically limited to the most populated and accessible areas - localities and territories adjacent to roads with good quality coverage. The third system consists of hyperlinks to photos and video clips, designed as placemarks. The density of signs indirectly characterizes the suitability, significance and popularity of objects for recreation and tourism. The fourth and fifth systems are three-dimensional objects and terrain models that form the presence effect. Specific information in this system, as well as in satellite images, is not clearly present - through a visa-assessed level of improvement, the attractiveness of architecture. Currently, the development of systems is technologically limited to the most populated and accessible areas - localities and territories adjacent to roads with good quality coverage. 


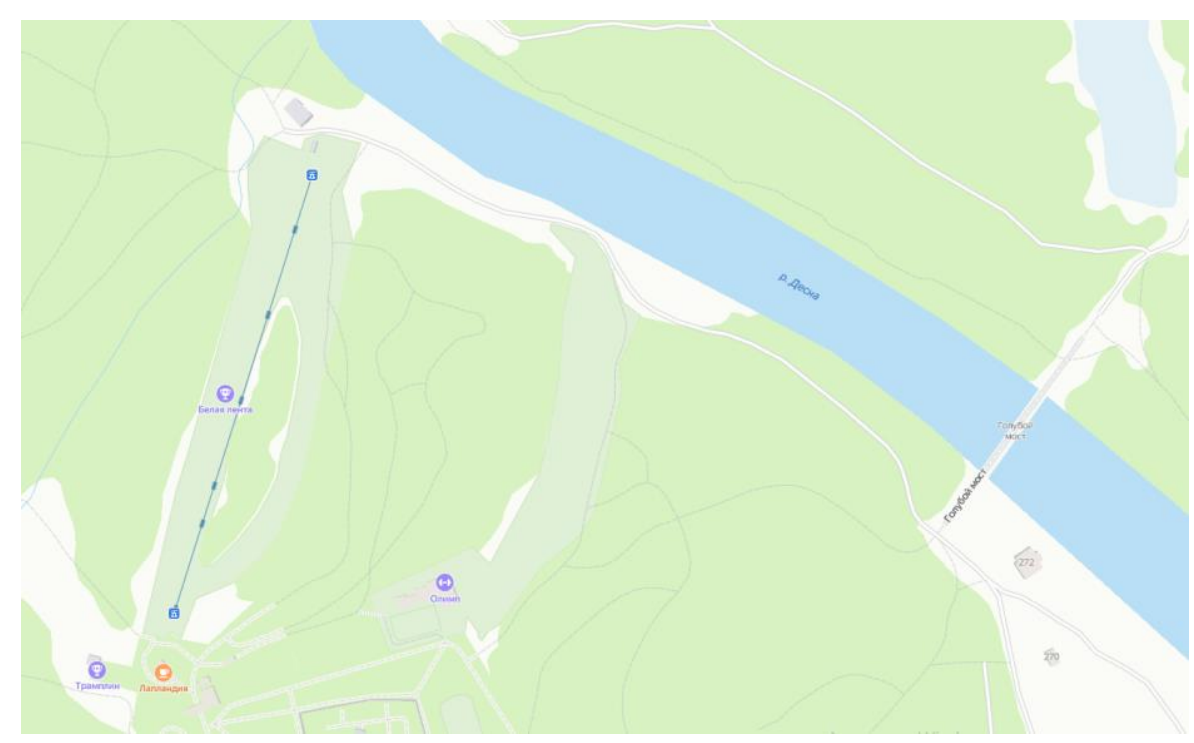

Fig. 2. Features of information about the area on Yandex maps. The points of interest and objects of the service sector are marked. Information about the landscape, road network features (terrain, water feature) is not explicitly expressed.

The features listed above and a number of other factors that are not directly related to the properties of geoportals allowed these information resources to significantly displace map models as a source of information about the area. Topographic maps and plans retain the most stable positions as sources of quantitative information, primarily about natural objects. The content of topographic maps and plans was formed on the basis of integration of various data sources - geodetic survey, land management, forest management, hydrological measurements, stock engineering materials. Geoportals allow you to integrate information from these sources in thematic layers, although the task of repeating, and possibly surpassing topographic maps and plans for the amount of special information can be considered only as one of the likely directions for the development of modern spatial models. The scale and complexity of data integration is justified by a significant increase in the efficiency of theoretical and applied geographical research.

\section{Conclusion}

The formation of popular geoportals as sources of information follows changes in society, summarized in the results of sociological research [12]. Free labor migration, readiness to change places of life and work, popularity of tourist trips and trips creates a demand for accessible and easy-to-use information resources about the world from people with different levels of geographical, including cartographic literacy. The huge volume of previously created cartographic images and satellite images, combined with 
computer processing tools, ensures that the demand is met through the organization of geoportals.

The content, design methods and technologies for managing geoportals are still formed intuitively, in active interaction with visitors, but based on the experience of traditional "paper" cartography. In the presentation of information, the utilitarian approach prevails - in models of the surrounding world on geoportals, techniques of "classic" cartographic research and graphic tools are used, which provide the consumer with a visual representation of the area and fast, simple navigation [13]. The probability of incorrectly determining the properties or location of objects is minimized.

Geo-images undergo a kind of user-generated generalization - graphical variables of conventional signs or additional visual means highlight objects that have the greatest value and (or) attractiveness, while others are hidden against the General background. At the same time, the local use of cartographic works and satellite images in hybrid geo-images has created an interesting phenomenon - a huge amount of potentially available information (about the relationships of objects and the laws of spatial placement), the demand and availability of which increases depending on the user's training and experience.

In the near future, the growth of integration of terrain data in geoportals will face new restrictions and scientific and methodological tasks that require original algorithms. The nature of the sources of restrictions differs significantly. To convey some information about the natural landscape (soil, vegetation), detailed research materials are not available; for elements of the cultural landscape, on the contrary, special approaches will be required to visualize a lot of factual information (including difficult to formalize, for example, expert assessments of the attractiveness of the landscape); for territories in General, the problem will be the need to create" convenient " for electronic mapping of localized objects and phenomena and generalized properties of large areas of terrain. The prospects for the development of geoportals are associated with the construction of semantic links of geographical objects placed on different information resources. It is probably the search for ways to integrate geographical information that will enrich the science of geographical systems with new ideas [14, 15, 16, 17].

\section{References}

1. Antonov, V., Zatyagalova, V., Zahvatov, M., Pyatkin, F.: Geoportal kak tochka vhoda v infrastrukturu prostranstvennyh dannyh. Interekspo Geo-Sibir 1, 1-4 (2014). In Russ.

2. Kadochnikov A., Yakubaylik, O.: Servis-orientirovannye web-sistemy dlya obra-botki geoprostranstvennyh dannyh. Vestnik NGU. Seriya: Informacionnye tekhno-logii 1, 37-45 (2015). In Russ.

3. Maguire, J., Longley, A.: The emergence of geoportals and their role in spatial data infrastructures. Computers, Environment and Urban Systems 29, 3-14 (2005).

4. Tait, G.: Implementing geoportals: applications of distributed GIS. Computers, Environment and Urban Systems 29, 33-47 (2005).

5. Berlyant A.M.: Teoriya geoizobrazhenij. GEOS, Moscow (2006). In Russ.

6. SASGIS Homepage, http://www.sasgis.org/ last accessed 2020/06/11.

7. 2 GIS Homepage, https://2gis.ru/ last accessed 2020/06/15. 
8. GoogleMaps Homepage, http://www.google.ru/maps/ last accessed 2020/07/05.

9. Yandex Karty Homepage, https://yandex.ru/maps/ last accessed 2020/07/10.

10. Uslovnye znaki dlya topograficheskoj karty masshtaba 1:10000. «Nedra» (Glavnoe upravlenie geodezii i kartografii pri Sovete Ministrov SSSR), Moscow (1977). In Russ

11. Uslovnye znaki topograficheskih planov dlya topograficheskih planov masshtabov 1:5000, 1:2000, 1:1000, 1:500. Nedra (Glavnoe upravlenie geodezii i kartografii pri Sovete Ministrov SSSR), Moscow (1977). In Russ.

12. Urri, J.: Mobil'nosti. Praksis, Moscow (2002). In Russ.

13. Lisitsky, D., Katsko, S.: Naznachenie i osobennosti cifrovogo kartograficheskogo izobrazheniya v geoinformacionnom kartografirovanii. Interekspo Geo-Sibir' 4, 22-28 (2005). In Russ.

14. Matveev, A., Yakubaylik, O.: Razrabotka veb-prilozheniya dlya obrabotki i predstavleniya prostranstvennyh metadannyh geoportala. Sibirskij zhurnal nauki i tekhnologij 2 (42), 4854 (2012). In Russ.

15. Bogdanovic, M., Stanimirovi, A., Stoimenov, L.: Methodology for geospatial data source discovery in ontology driven geoinformation integration architectures. Web Semantics: Science, Services and Agents on the World Wide Web 32, 1-15 (2015).

16. Peisheng, Zh., Liping, Di., Genong, Yu., Peng, Yu., Yaxing, W., Wenli, Y.: Semantic Webbased geospatial knowledge transformation. Computers \& Geosciences 35, 798-808 (2009).

17. Reitsma F., Laxton J., Ballard S., Kuhn W., Abdelmoty A.: Semantics, ontologies and eScience for the geosciences. Computers \& Geosciences 35, $706-709$ (2009). 